\title{
COMPRENSIÓN DE TEXTOS ESCRITOS: RECONCEPTUALIZACIONES EN TORNO A LAS DEMANDAS DEL SIGLO XXI
}

\author{
Comprehension OF Written TeXts: ReConCEPTUALIZING $21^{\text {st }}$ CENTURY CHALLENGES \\ COMPRÉHENSION DE TEXTES ÉCRITS : RECONCEPTUALISATIONS EN FACE DES DEMANDES \\ DU XXI ${ }^{\text {ĖEE }}$ SIÈCLE
}

\author{
Giovanni Parodi \\ Doctor en Lingüística, Pontificia \\ Universidad Católica de Valparaíso, \\ Chile. \\ Profesor titular, Instituto de \\ Literatura y Ciencias del Lenguaje, \\ Pontificia Universidad Católica de \\ Valparaíso, Chile. \\ giovanni.parodi@pucv.cl \\ https: //orcid. \\ org/0000-0003-2403-7038
}

\section{Tomás Moreno-de-León} Estudiante doctorado en Lingüística, Pontificia Universidad Católica de Valparaíso, Chile tomas.moreno.d@mail.pucv.cl https: //orcid.

org/0000-0003-4931-971X

\section{Cristóbal Julio}

Estudiante doctorado en Lingüística, Pontificia Universidad Católica de Valparaíso, Chile. cristobal.julio@pucv.cl https://orcid. org/0000-0002-4723-0271

Este texto es resultado del proyecto FoNDECYT 1170623 (2017-2020), titulado: "¿̇Existen diferentes rutas de lectura de textos multisemióticos en profesionales de diferente procedencia disciplinar?".

\begin{abstract}
RESUMEN
El vertiginoso avance de los desarrollos tecnológicos a inicios del siglo XXI ha impuesto desafíos inmensos para los investigadores de la comprensión de textos escritos desde un enfoque de alfabetizaciones múltiples, tanto académicas como profesionales. Ahora se hace apremiante examinar las exigencias que implica la comprensión lectora no solo en los formatos en papel, sino también en diversos soportes electrónicos y con propósitos de lectura diversos. Asimismo, es perentorio analizar la comprensión de múltiples textos y géneros eventualmente heterogéneos y multimodales. En la actualidad, debido al acceso inmediato y a la disponibilidad en línea de una creciente cantidad de información, tanto general como especializada, la comprensión de estos textos impone demandas incrementales para el sistema cognitivo humano. Este artículo busca abordar dicha complejidad, atendiendo, en un primer momento, a la conceptualización del macroproceso de la comprensión, con foco en un único texto eminentemente verbal, hasta considerar el procesamiento de múltiples textos multimodales y multimediales, los géneros del discurso académico y profesional, y los textos que caracterizan el siglo XXI, incluyendo los desafíos que este trae para los lectores en la actualidad y en el futuro.
\end{abstract}

Palabras clave: comprensión lectora; textos escritos; multimodalidad; multimedia; géneros discursivos; objetivos de lectura; discurso académico.

\begin{abstract}
The rapid pace of technological developments at the beginning of the $21^{\text {st }}$ century has posed tremendous challenges for researchers concerned with written texts comprehension from an academic and professional multiliteracy approach. It is now imminent to acknowledge the demands that reading comprehension implies not only for paper formats, but also for diverse electronic media, and diverse reading purposes. It is also vital to consider the comprehension of multiple texts and of eventually heterogeneous and highly multimodal genres. Nowadays, due to the immediate access and online availability of growing general and specialized information, the comprehension of such texts imposes incremental demands to human cognitive systems. This article seeks to address that complexity beginning with the conceptualization of the comprehension macroprocess, as it involves an eminently verbal single text, and continuing with the processing of multiple multimodal and
\end{abstract}

Recibido: 2019-08-08 / Aceptado: 2020-06-19 / Publicado: 2020-09-15

https://doi.org/10.17533/udea.ikala.v25n03a10 
multimedia texts, academic and professional genres, and the texts that characterize the $21^{\text {st }}$ century, including the challenges that this represents to readers now and in the future.

Keywords: reading comprehension; multimodality; multimedia; discourse genre; reading objectives; academic discourse.

\section{Résumé}

Le rythme rapide du développement technologique en ce début de xxième siècle a imposé aux chercheurs d'immenses défis pour comprendre les textes écrits à partir d'une approche d'alphabétisation multiple, tant académique que professionnelle. Il est maintenant imminent de réaliser les exigences de la compréhension de la lecture non seulement en format papier, mais aussi dans divers médias électroniques et à des fins de lecture variées. Il est également impératif de prendre en compte la compréhension de textes multiples, et éventuellement de genres hétérogènes et multimodaux. Aujourd'hui, en raison de l'accès immédiat et de la disponibilité en ligne d'une quantité croissante d'informations générales et spécialisées, la compréhension de ces textes impose des exigences supplémentaires au système cognitif humain. Cet article cherche à aborder cette complexité en abordant d'abord la conceptualisation du macroprocessus de compréhension, en se concentrant sur un seul texte, éminemment verbal, puis en considérant le traitement de multiples textes multimodaux et multimédias, des genres de discours académique et professionnel, et des textes qui caractérisent le Xxième siècle, y compris les défis que cela représente pour les lecteurs d'aujourd'hui et de demain.

Mots-clés : compréhension de lecture ; multimodalité ; multimédia ; genre du discours; objectifs de lecture ; discours académique. 


\section{Introducción: la comprensión de textos escritos como macroproceso}

La comprensión textual, contrario a lo que suele pensarse, no es una habilidad que se desarrolla solo durante la educación primaria y, una vez alcanzado un nivel operacional o funcional, luego no requiere mayor entrenamiento. Muy a la inversa: debido a su carácter multidimensional, la competencia lectora está en permanente desarrollo y se encuentra dirigida a diferentes metas y guiada por múltiples objetivos; incluye un conjunto de estrategias en permanente expansión, que los lectores perfeccionan a lo largo de la vida de acuerdo con las demandas de los diversos géneros discursivos en distintos ambientes.

En un contexto mundial en progresivo avance tecnológico, en la actualidad, la comprensión de textos escritos debe visualizarse como una lectura de múltiples textos multimodales y multimediales, como parte de una competencia estratégica fundamental. Esta visión integral parece ser más relevante que nunca. Esto se debe a que los lectores deben saber, por ejemplo, cómo corroborar la información de diferentes documentos para determinar su exactitud o verificar los datos entregados en ellos (Braasch et al., 2018; Parodi, 2014; Parodi y Julio, 2016; Salmerón et al., 2018; Strømsø y Bråten, 2014). Ello cobra particular relevancia debido a que la lectura cotidiana, en el mundo tecnológico contemporáneo, exige a los lectores poder seleccionar, evaluar e integrar información, de distintas fuentes y géneros, en diferentes medios y dispositivos. Esta aproximación teórica ha sido crucial en la reconceptualización de lo que significa comprender y de cómo se operacionaliza.

En este sentido, la comprensión de textos escritos puede —en general- ser definida como un macroproceso multidimensional, en el que es posible distinguir diversos planos o dimensiones, todos fuertemente interrelacionados. Desde esta aproximación integral contemporánea se identifica - al menos- una dimensión biológica, otra cognitiva, una textual y una social.
Desde esta perspectiva, la comprensión es biológica, porque ocurre en el cuerpo del lector y, en particular, en el cerebro humano, aunque todo el proceso comprensivo es corpóreo en un sentido integral (De Vega, 2005; Zwaan, 2004). Tiene una dimensión cognitiva, debido a que los procesos que acontecen van más allá de la corporeidad e involucran a la mente y la conciencia del lector, tanto como a sus emociones y motivaciones (De Vega et al., 2008). Junto a lo anterior, la comprensión también es textual, ya que el objeto de cognición es un texto, producto de la actividad humana del hablar (Coseriu, 1992). Dicho texto escrito debe ser entendido desde una concepción contemporánea, es decir, desde una conceptualización compleja, que lo entiende como una unidad lingüística y semántica, constituida por múltiples sistemas de significación, y que no se restringe solo a las palabras (Halliday, 1978; Halliday y Hasan, 1985). Finalmente, pero no en último lugar, la comprensión es un acto social, que implica el reconocimiento de un contexto físico, de los roles que desempeña el lector y, eventualmente, de los roles de otros participantes del acto lector (Van Dijk y Kintsch, 1983).

Así, en sentido técnico, la comprensión exitosa implica, por parte del lector, la construcción de una representación mental coherente (modelo de situación) de un texto, a la luz de sus conocimientos previos y orientada por objetivos de lectura, ya sea del propio lector o establecidos externamente (Kintsch, 1998; Kintsch y Van Dijk, 1978; Parodi, 2010, 2014; Van Dijk y Kintsch, 1983). En la construcción de tal representación mental compleja, el lector lleva a cabo una amplia variedad de procesos de diversa naturaleza y jerarquía, algunos de ellos automáticos y otros estratégicos (Graesser, 2007; Graesser et al., 1994;).

En la actualidad, existe mayor consenso en que comprender un texto escrito constituye una actividad intencionada y guiada por los propósitos del lector, aunque no haya un acuerdo definitivo respecto del grado de participación consciente del lector en todo el proceso de lectura (Rayner $e t$ al., 2012). En esta 
línea, si se adopta de modo radical el modelo de construcción-integración de Kintsch (1988, 1998), se tiende a difuminar el rol de las estrategias, aunque, posteriormente, ha reconocido un mayor dinamismo de dichos procesos:

Comprehension in this technical sense is automatic meaning construction via constrain satisfaction, without purposeful, conscious effort. Normal reading involves automatic comprehension, as well as conscious problem solving whenever the pieces of the puzzle do not fit together as they should (Kintsch, 2013, p. 808).

En este contexto, cabe señalar que la investigación interdisciplinaria en comprensión ha avanzado decididamente en los últimos 40 años y ha logrado abordar en forma progresiva, con mayor profundidad, un objeto de estudio complejo. En este camino, se ha progresado desde enforcarse en procesos de memoria y reconocimiento léxico, enmarcado en estrechos paradigmas experimentales que, en muchos casos, empleaban "textoides" (textos creados ad hoc para determinados experimentos), a estudiar el procesamiento del lenguaje natural, la resolución de problemas, el razonamiento y el aprendizaje profundo en contextos progresivamente más ecológicos y naturalísticos ("lectura en el mundo real"), y con atención a los géneros del discurso y la disciplinariedad. También se contempla la lectura digital y en múltiples dispositivos, y los desafíos que ha provocado leer en papel y en nuevos formatos y géneros dinámicos y que han llevado a los lectores a nuevas demandas y a desarrollar nuevas estrategias y recursos $(v . g$., Baron et al., 2017; Parodi et al., 2019; Salmerón y Delgado, 2019).

Ahora bien, en este artículo, el foco está puesto en cómo un lector típico ideal, con habilidades estándar y motivado por la lectura, procesa información escrita, de diversa naturaleza, mientras lee. No atendemos aquí a la lectura inicial ni a dificultades o patologías de lectura. El recorrido propuesto va desde la comprensión de un texto eminentemente verbal, los mecanismos inferenciales como núcleo de la lectura comprensiva, el procesamiento de un texto multimodal, hasta la comprensión de múltiples textos de naturaleza multimodal y multimedial, atendiendo a los géneros académicos y profesionales. Este recorrido no implica que un lector típico sea necesariamente un lector altamente competente y exitoso, ya que - como puntualizamos más arriba - la comprensión debe desarrollarse a lo largo de toda la vida y - muchas veces - requiere apoyos y soporte para el desarrollo de estrategias adecuadas (Magliano $e t$ al., 1999; McNamara, 2007; Salmerón y Llorens, 2019). Por ello, lo concebimos como un lector típico, pero idealizado, como suele ser el que supone la mayoría de los modelos teóricos acerca de la comprensión ( $v$. g., Kintsch, 1998; Van Dijk y Kintsch, 1983; Zwaan y Radvansky, 1998).

\section{La comprensión a partir de un único texto eminentemente verbal: las inferencias}

La mayor parte de los esfuerzos en la investigación de la comprensión de textos escritos ha estado abocada al estudio de los procesos cognitivos implicados en la lectura de un único texto de naturaleza eminentemente verbal (compuesto preferentemente solo de palabras). En este sentido, existe una amplia y variada disponibilidad de teorías y modelos de comprensión que describen, con mayor o menor detalle, los procesos y subprocesos que implica la lectura de los diversos componentes verbales de un texto determinado, predominantemente de tipo narrativo $(v . g$., Britton y Graesser, 1996; McNamara y Magliano, 2009; Parodi, 2014; Van den Broek y Gustafson, 1999).

En estos modelos, se suelen describir los ciclos de procesamiento en que se atiende a la microestructura textual y los diferentes niveles incrementales de complejidad del procesamiento, desde la identificación de palabras hasta la asignación de significado a cadenas oracionales en la construcción de una macroproposición textual. Para ello, se han propuesto distintos niveles de representación cognitiva o mental, que buscan dar cuenta de estos ciclos recursivos de procesamiento que se ejecutan a partir de la lectura de un texto (v. g., código de superficie, base de texto, modelo 
de situación, género del discurso). En general, se ha dado cuenta de múltiples tipos de conexiones mentales que se establecen a partir de la información textual, con el fin de llegar a construir una representación mental coherente.

Con este propósito, se ha identificado la inferencia como un mecanismo cognitivo central para el establecimiento de la coherencia textual. Los modelos y las teorías sobre la comprensión han ido logrando, en forma progresiva, especificar de mejor manera los diversos procesos inferenciales y sus tipologías o taxonomías, basadas preferente o exclusivamente a partir del modo verbal y con predominancia de textos narrativos (Graesser et al., 1994; GutiérrezCalvo, 1999; León y Pérez, 2003; McKoon y Ratcliff, 1992; Van Dijk y Kintsch, 1983).

Durante mucho tiempo, se optó por el estudio de los cuentos, pues se asumía que en ellos se representaba de mejor modo el tipo de lenguaje cotidiano de naturaleza narrativa que un lector promedio debía manejar. A modo de ejemplo, en la Figura 1 revisamos dos tipos de inferencias: pronominales (pronombre personal y pronombre neutro) y causales (marcada y no marcada).

\section{1a. María y José no llegaron a tiempo para tomar el último tren. Ellos debieron conseguir un hotel para pasar la noche.}

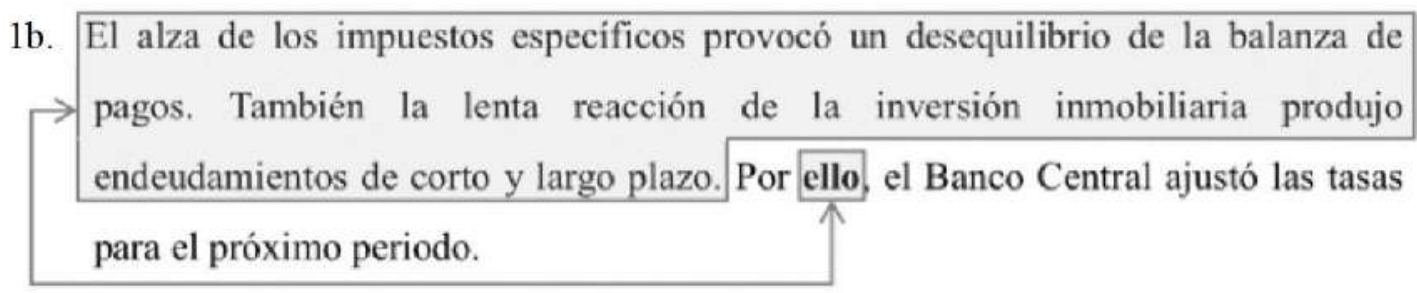

Figura 1 Ejemplos de inferencias pronominales

En el ejemplo 1a, para comprender este texto, se debe conectar anafóricamente el pronombre personal (ellos) con sus dos antecedentes (María y José) y, de este modo, lograr brindar coherencia referencial al texto; en otras palabras, mediante esta inferencia anafórica, el lector podrá saber que se sigue hablando de las personas indicadas en el primer segmento discursivo.

Por su parte, en el texto del ejemplo $1 b$, se requiere también generar una inferencia anafórica pronominal, pero de distinta naturaleza. Se trata de un pronombre neutro en una función encapsuladora con antecedente complejo y extenso, que involucra a las dos oraciones previas. Así, para construir coherencia relacional, el lector de este segundo texto debe ejecutar una inferencia de mayor complejidad y jerarquía, y lograr reconocer al antecedente de pronombre neutro en un extenso segmento discursivo anterior. Solo si el lector logra generar una inferencia que establezca esta conexión, podrá entonces comprender la razón del ajuste de las tasas para el próximo periodo.

Otro tipo de inferencia conectiva es la que le permite al lector enlazar causalmente dos segmentos del texto y comprender que uno establece la causa física del otro, construyendo así la coherencia relacional. Veamos los dos textos que se muestran en la Figura 2.

En $2 \mathrm{a}$ y $2 \mathrm{~b}$, el lector debe conectar ambos segmentos discursivos, generando inferencias causales (marcada en 2 a con el marcador discursivo porque, 
2a. El señor Romera no vendrá al club esta noche porque su madre se encuentra muy enferma.

2b. El vehículo derrapó aceleradamente por la ladera oriental. [XXX] Dos vacas y una oveja resultaron con heridas de gravedad y el establo fue dañado seriamente.

Figura 2 Ejemplos de inferencias causales

y no marcada en $2 b$, con yuxtaposición de dos oraciones).

Como se puede apreciar en estos ejemplos, las inferencias, mediante diversos ciclos de procesamiento, proveen al lector de herramientas cognitivas para enlazar la información textual y construir la coherencia (muchas veces por medio de pistas lingüísticas explícitas), lo que dota al texto de sentido y genera la elaboración de una representación mental de la información del texto.

Menor atención han recibido las taxonomías de inferencias en virtud de la variación existente a partir de diferentes géneros discursivos y según la diversidad disciplinar. Por ejemplo, entre la y $1 \mathrm{~b}$ se aprecia una variación del tipo de inferencia que responde esencialmente al tópico y al género. Es muy probable que una inferencia pronominal neutra, como en $1 \mathrm{~b}$, sea más prototípica de un género de reporte económico de tipo descriptivo (economía) y no de un cuento narrativo (literatura). Pese a algunos intentos por extender el modelo construccionista más allá de lo narrativo (Graesser y Bertus, 1998; Otero et al., 2002), existe escasa investigación al respecto y queda un importante nicho a ser estudiado de forma sistemática.

Tal como indica Kintsch (2013), la amplia y larga trayectoria de estudios centrados en textos escritos preferentemente verbales enfrenta algunas limitaciones, aunque sin duda estos tremendos desarrollos han llevado a fundamentales avances científicos y aplicados: "This deficiency is a major reason why much of the research on text comprehension has focused on the verbal aspects, neglecting the role of mental imagery for all its acknowledged significance" (Kintsch, 2013, p. 809).

En los siguientes apartados nos enfocamos en la comprensión de textos multimodales y en el procesamiento de múltiples textos (multimodales). Posteriormente, atendemos a la importancia de los objetivos del lector y la comprensión de textos académicos y profesionales.

\section{La comprensión como procesamiento de un texto multimodal}

A diferencia de la comprensión de un único texto constituido solo por palabras, no se ha alcanzado un amplio nivel de consenso en torno a cómo se construye una representación mental a partir de un único texto multimodal, en el que pueden coexistir múltiples modos. Diversas propuestas teóricas han desarrollado modelos que dan cuenta de cómo el modo verbal y las imágenes son procesados (Mayer, 2005; Pinker, 1990; Sadoski y Paivio, 2004; Schnotz, 2014). En términos generales, se suele coincidir en proponer dos vías o rutas de acceso de información: un canal verbal y un canal de imágenes. Estas propuestas han recibido ciertas críticas, por lo aparentemente limitado del acceso único en dos vías, pues se argumenta que los modos constitutivos de un texto exigen al sistema cognitivo humano mucho más que solo dos canales (Dehaene, 2010; Parodi, 2014; Parodi y Julio, 2015). En la Figura 3 se busca ilustrar la multiplicidad de sistemas representacionales que potencialmente se hallan en un texto escrito, y la disponibilidad cognitiva y cerebral de representar información de naturaleza heterogénea. 


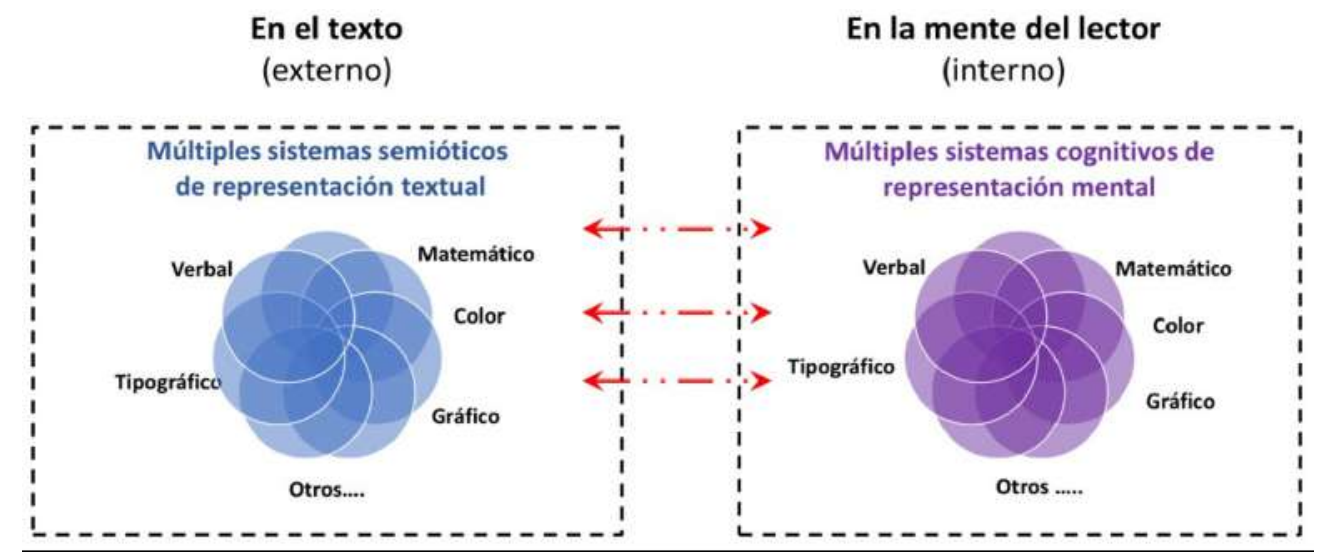

Figura 3 Múltiples sistemas textuales y cognitivos

Como se puede apreciar, un texto escrito es una fuente potencial de distintos sistemas representacionales, los cuales deben ser atendidos y procesados por el lector, en virtud de diferentes mecanismos cognitivos y cerebrales de registro y codificación. En la actualidad, aún no disponemos de un conocimiento profundo y sistemático ni de los rasgos textuales multimodales ni de los sistemas de representación y procesamiento mental que operarían para registrar e integrar tal información de diversa naturaleza. Tampoco se cuenta con antecedentes científicos detallados de cómo se conecta dicha información textual proveniente desde múltiples modos con los sistemas cognitivos humanos.

Pese a ello, existen diferentes propuestas que, en términos generales, permiten señalar que se comprende mejor y se genera mejor aprendizaje cuando la información se muestra en más de un modo (principio multimedial) (Mayer, 2005). De esta manera, la teoría cognitiva del aprendizaje multimedial (Mayer, 2009) y el modelo integrado de la comprensión del texto e imagen (Schnotz, 2014) coinciden en describir este proceso como la construcción e integración de las informaciones contenidas en los diversos modos que hacen parte de un texto. Ello, a partir de la interacción entre el módulo cognitivo de la memoria de trabajo (decodificación de los textos recogidos ocularmente a partir de palabras e imágenes) y el módulo cognitivo de la memoria de largo plazo (patrones de lectura y conocimiento previo).
Por otro lado, la teoría del código dual (Sadoski y Paivio, 2004) plantea que esta comprensión se construye a partir de dos códigos, uno especializado en lo verbal y otro para el resto de los modos.

Complementaria a los modelos anteriores, la teoría de la comunicabilidad (Parodi, 2011, 2014) pone especial énfasis en el eje del contexto, al explicar cómo se comprende un único texto multimodal, es decir, si bien reconoce la importancia de los ejes del lector y del texto, va más allá, integrándolos en una visión psicosociolingüística. En específico, esta teoría propone que la comprensión multimodal se construye a partir de tres supuestos: 1) el de la cognición situada: lectura de textos ecológicos auténticos, donde el lector tiene objetivos de lectura propios; 2) el de la interactividad: fuentes de información, lector, texto, contexto, formato de lectura, y 3 ) el de la socioconstructividad: desarrollo biológico en contextos sociohistóricos particulares.

Siguiendo la tesis del principio multimedial, Habel y Acartürk argumentan que "bumans make inferences not purely on statistical data; rather, they interpret the data depending on characteristics of the communicative mode" (2011, p. 11). Por esta razón, como en la comprensión de un único texto eminentemente verbal, las inferencias son fundamentales en el proceso de construcción de significado de textos propiamente multimodales. Varios estudios han proporcionado evidencia 
empírica acerca de este principio ( $v$. g., Habel y Acartürk, 2011; Mason et al., 2013; Mayer, 2009; Parodi y Julio, 2015, 2016).

Para ejemplificar lo anterior, consideremos dos géneros multimodales de economía: el "Informe anual del Fondo Monetario Internacional" (IAFMI) y el "Informe mensual de estadísticas monetarias y financieras" (IMEMF) del Banco Central de Chile (Molina, 2018; Moreno-deLeón, 2018).

En el caso del IAFMI, la movida retórica más importante realiza una evaluación de un tema en un periodo pasado y la estimación de cómo se comportará en un periodo futuro (Molina, 2018) (Figura 4).

De acuerdo con el principio multimedial (Mayer, 2005), para comprender este segmento discursivo sería necesario que los lectores construyeran una representación mental coherente entre el segmento verbal $(v \cdot g$. constituido a partir palabras, números y porcentajes, diversas tipografías) y el segmento gráfico $(v . g$., constituido por números, porcentajes, líneas, color, diferentes tipografías y signos matemáticos). De este modo, las inferencias intersistémicas son fundamentales para tejer
España, uno de los países más afectados por la crisis financiera mundial en la zona del euro, ha tenido una recuperación extraordinaria. La economía creció más de $3 \%$ tanto en 2015 como en 2016, y se espera que en 2017 recupere el nivel de crecimiento del PIB previo a la crisis (gráfico 1.15).

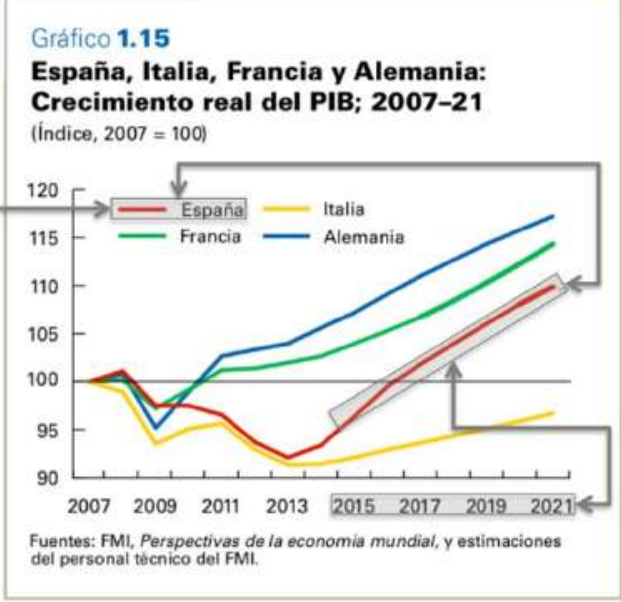

Figura 4 Segmento discursivo del "Informe anual del Fondo Monetario Internacional". PIB: producto interno bruto; FMI: Fondo Monetario Internacional

Fuente: Adaptado de Fondo Monetario Internacional (2017).

el significado del texto multimodal. Por ejemplo, en el segmento discursivo de la Figura 4, un lector debería identificar que las palabras proporcionan información acerca de un solo país, España; que la fluctuación de crecimiento real del producto interno bruto (PIB) está ilustrada con el color rojo, y que el gráfico presenta información no discutida o mencionada por las palabras.

Tomando en cuenta este ejemplo, Parodi y Julio (2015) argumentan que es probable que los lectores puedan comprender un segmento discursivo mediante una lectura centrada principalmente en un solo modo. En específico, es factible que los lectores lleven a cabo mejores resúmenes sise enfrentan a un texto constituido, por ejemplo, solo por el modo gráfico. Sin embargo, al leer un texto constituido por dos modos, como el que se muestra en la Figura 4, los lectores podrían concentrar mayor atención al modo verbal. En otras palabras, pese a que los lectores podrían beneficiarse más de un texto al leer el gráfico, cuando leen un segmento 
discursivo con palabras y un gráfico, aquellos tienden a leer más el modo verbal. A este fenómeno se le conoce como principio logocentrista, el cual consiste en un adiestramiento del ojo que hace que los lectores presten más atención al modo verbal de un texto, en desmedro de los otros también disponibles (Parodi y Julio, 2016). Estos resultados son consistentes con la evidencia reportada en diversas investigaciones sobre procesamiento multimodal, como lo resumen Alemdag y Cagiltay (2018), en una revisión de más de cincuenta estudios sobre aprendizaje multimedial con el uso de eyetracking: "The common finding of the studies was that learners give more attention to text than to pictures. This implies that people prefer a more text-dominant learning process in multimedia environments" (Alemdag y Cagiltay, 2018, p. 422).

Otro ejemplo de comprensión multimodal se puede dar en el caso del IMEMF. Este género tiene como movida retórica más importante la constatación de tendencias (Figura 5).

\section{Stock colocaciones: noviembre 2018}

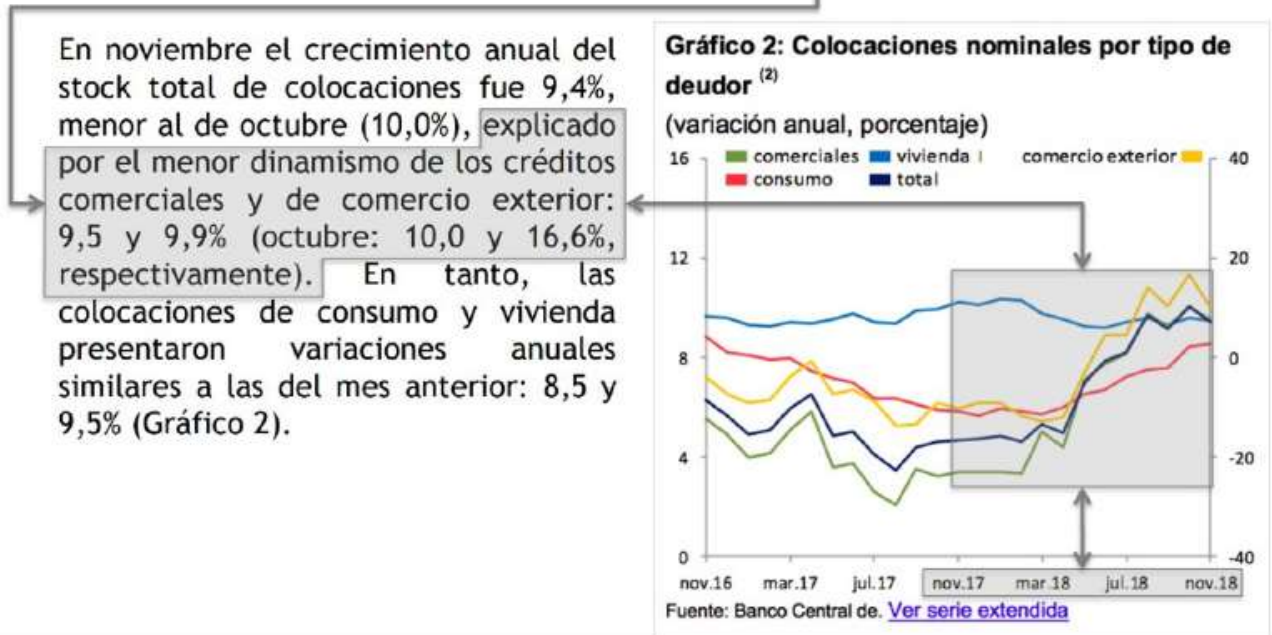

Figura 5 Segmento discursivo del "Informe mensual de estadísticas monetarias y financieras"

Fuente: Adaptado de Banco Central de Chile (2018).

De esta manera, la comprensión exitosa de este segmento discursivo podría estar relacionada con los esfuerzos cognitivos por integrar la información que está contenida en el modo verbal y en el modo gráfico (Mason et al., 2013). Especialmente en este tipo de informe, las inferencias causales intermodales cobran gran relevancia para establecer conexiones textuales (Habel y Acartürk, 2011). Siguiendo esta postura, lectores enfrentados a un objetivo de lectura como "leer para responder preguntas de opción múltiple acerca de las colocaciones nominales", probablemente intentarían encontrar más conexiones entre el modo verbal y el gráfico. De esta forma, los lectores de este segmento discursivo deberían identificar que el crecimiento de las colocaciones nominales se explica por el menor dinamismo de los créditos comerciales y de comercio exterior. Otras investigaciones han abordado textos de distintas fuentes de otras disciplinas, como historia, matemáticas y ciencias naturales, con desafíos diversos en cuanto a formatos y artefactos (Braasch et al., 2018).

Así, la mayoría de las propuestas que buscan explicar la comprensión y el aprendizaje desde un único texto multimodal se adscriben a la teoría cognitiva del aprendizaje multimedial, la cual, a grandes rasgos, se puede sintetizar en que "people learn more 
deeply from words and pictures than from words alone" (Mayer, 2005, p. 31). No obstante, es muy precaria la información científica disponible en la actualidad sobre los procesos inferenciales que ocurren en la construcción de una representación mental multimodal: por ejemplo, ¿qué tipos de inferencias operan entre las palabras y ciertos segmentos de un gráfico? Varios investigadores, siguiendo categorías lingüísticas, postulan que algunos de estos procesos cognitivos serían similares a los que ocurren a partir de un texto verbal (Martinec y Salway, 2005; Royce, 1999) y, por ejemplo, asumen que existen - entre otras - inferencias de tipo causal (Habel y Acartürk, 2011).

\section{La comprensión como procesamiento de múltiples textos verbales y multimodales}

En la misma línea descrita al inicio de este artículo, el estudio científico de la comprensión de más de un texto también se inició atendiendo a textos preferentemente verbales. Uno de los primeros estudios que innovaron el foco de interés que tenían las investigaciones más tradicionales de un único texto eminentemente verbal, fue el que llevó a cabo Wineburg (1991), en el cual se planteó entender cómo es que se distinguen las estrategias de lectura por parte de lectores expertos y legos de la disciplina de historia. A poco más de 25 años de este artículo seminal, se reconocen al menos dos principales líneas de investigación: la evaluación de la confiabilidad de los textos (Wiley et al., 2009) y la de integración de textos (Britt y Sommer, 2004).

Si bien señalábamos que al conceptualizar el proceso de comprensión de un único texto multimodal solo se ha alcanzado un consenso relativo, existe mucho menor acuerdo cuando se trata de definir el modo en que se procesan dos o más textos de naturaleza verbal. Este nicho de investigación ha sido paulatinamente ocupado por la necesidad de explicar procesos de lectura más naturales, por ejemplo, el hecho de que, en la actualidad, los lectores tengan acceso a gran cantidad de información en línea, lo cual hace que se enfrenten potencialmente a múltiples textos que no han sido escritos necesariamente para ser comprendidos de manera interconectada. En este sentido, un informe económico escrito en 2010, en el que se reporta una crisis financiera, no fue construido para que un lector integrara su información con la de otro informe redactado en 2017; sin embargo, estas lecturas son bastante habituales, por ejemplo, para entender los cambios macro y microeconómicos.

$\mathrm{Al}$ respecto, Strømsø (2017) sugiere que los modelos de comprensión de múltiples textos (en nuestra opinión, eminentemente verbales) coinciden en explicar que la comprensión de dos o más textos es un proceso de construcción de la representación mental coherente de cada texto, de tal forma que el lector es capaz de recordar qué información se encuentra en cada texto, crear una representación mental de la estructura semántica entre los textos (modelo intertextual) y crear una representación mental de la relación entre los modelos situacionales planteados entre los textos (modelo de situaciones). Estas propuestas teóricas de la comprensión de múltiples textos (verbales) han explorado cómo es que distintas variables influyen en el proceso lector, como, por ejemplo, factores internos del lector (creencias acerca del tema, hábitos de lectura, motivación) y factores externos al lector (quién solicita la tarea de lectura, objetivo de lectura explícitamente proporcionado, dispositivos de lectura).

Comparativamente, la investigación centrada en la comprensión de múltiples textos de naturaleza multimodal ha sido menor y se registran escasos estudios que la aborden de este modo. Prueba de ello es lo señalado recientemente por List y Alexander (2018):

The literatures on multiple documents (MD) and multi-modal document (MMD) comprehension have identified an array of processes and competencies critical to living and learning in the 21 st century. Yet for too long, the MD and MMD literatures have continued along separate tracks, with few researchers tackling how students may make sense of information from multiple and multi-modal documents (p. 82). 
Al respecto, Rouet y Britt (2014) plantean una primera propuesta, en la que, además de la representación mental coherente de varios textos — similar a la de múltiples textos (verbales) explican que la comprensión de múltiples textos (multimodales) consiste en la construcción de un nuevo conocimiento, opinión o perspectiva, que le permite al lector tomar postura ante el tema que se está leyendo. En términos generales, en esta propuesta se reportan hallazgos en favor de que si bien la integración de múltiples textos multimodales podría parecer una tarea altamente

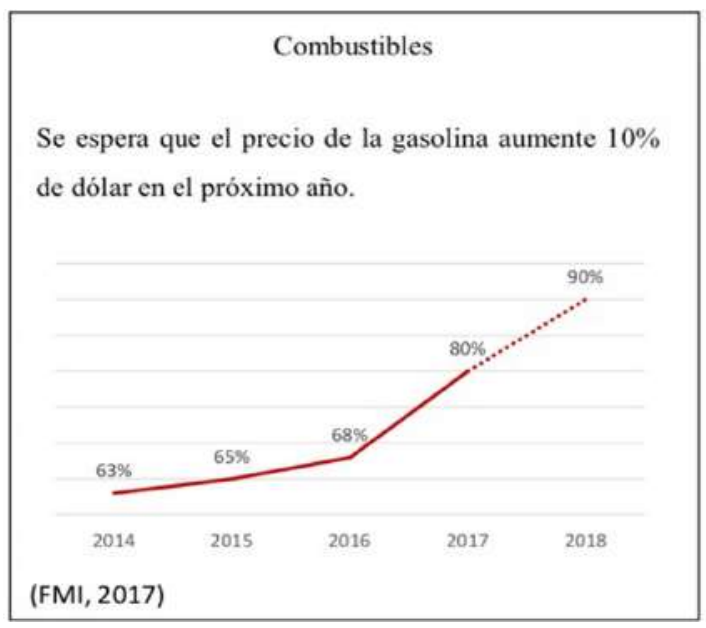

demandante, los profesionales de economía alcanzan un nivel intermedio y registran sobre el $60 \%$ de logro al leer dos segmentos discursivos multimodales cuando el objetivo de lectura es explícito, frente a un porcentaje de logro significativamente menor cuando el objetivo de lectura es general.

A modo de ejemplo, en la Figura 6 ilustramos las movidas retóricas más representativas de cada género. Del lado izquierdo se presenta un segmento textual del IAFMI, y del lado derecho, uno del IMEMF.

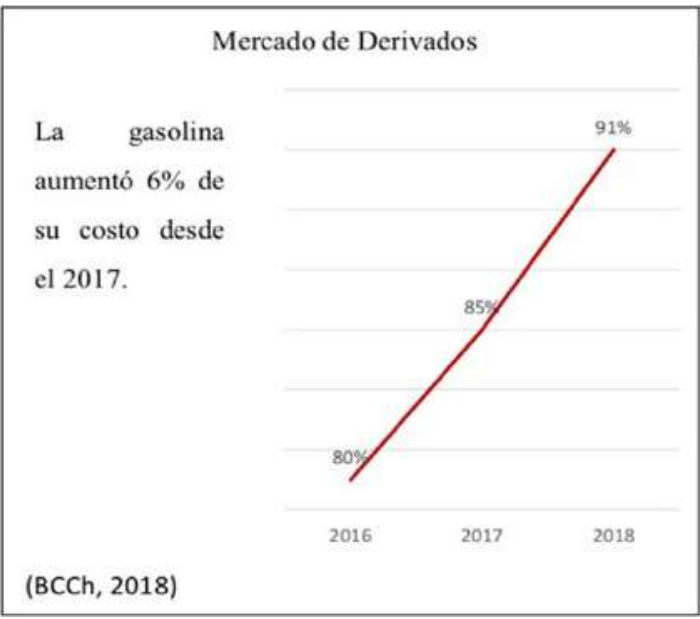

Figura 6 Segmentos discursivos del IAfmi y del imemF

Fuentes: Fondo Monetario Internacional (2017) y Banco Central de Chile (2018).

Desde nuestra perspectiva, enfrentados a estos segmentos discursivos, los lectores buscarían establecer conexiones entre ellos, orientados principalmente por un objetivo explícitamente proporcionado. Por ejemplo, para responder en forma exitosa al objetivo de lectura "leer para identificar en qué porcentaje el costo de la gasolina superó/no superó la estimación hecha en 2017", los lectores deberían construir una representación mental de ambos segmentos discursivos, en donde el que representa al IAFMI realiza una estimación, mientras que el que representa al IMEMF, constata. De lo contrario, los lectores podrían suponer que el identificar la diferencia de $4 \%$ entre la estimación del segmento discursivo del
IAFMI y la constatación del segmento discursivo del imemf sería la respuesta correcta. Pese a ello, la representación mental de los múltiples textos que deberían construir los lectores tendría que considerar en qué año fue publicado cada segmento y la realización retórica de cada uno; de esta manera, deberían identificar que la respuesta al objetivo de lectura explícitamente proporcionado es que no se superó en $4 \%$.

Cabe señalar que empleamos la expresión "objetivo de lectura explícitamente proporcionado”, pues esta propuesta se alinea teóricamente a las que sugieren que independiente del objetivo de lectura que se le proporcione a un lector, este 
autogestiona otra serie de objetivos que se pueden alinear o no al objetivo de lectura explícitamente proporcionado (Britt et al., 2018).

Ahora bien, en este progresivo proceso de reconceptualización, construir una representación mental interconectada a partir de múltiples textos multimodales constituye un proceso inherentemente intertextual de mayor exigencia,

[...] in which multiple sources of information are juxtaposed with one another, portions are evaluated and selected, and information is integrated as part of a process of updating the experts' mental model about the topic (Goldman et al., 2012, p. 357).

Las teorías de la comprensión de múltiples textos han propuesto extensiones críticas a los modelos de procesamiento de un único texto (Perfetti et al., 1999; Rouet y Britt, 2014), aunque aún no se integra de manera certera el componente multimodal.

\section{La comprensión de géneros del discurso} académico y profesional

Como se ha señalado, la investigación de la comprensión de textos escritos estuvo centrada durante muchos años en géneros narrativos. $\mathrm{La}$ atención a géneros académicos ha sido escasa y mucho menor la que aborda los géneros que se producen y circulan en ámbitos profesionales. Como se sabe, los géneros del discurso se construyen y transitan en varios ámbitos y revelan interesantes variaciones genéricas, incluso dentro de una misma disciplina (Parodi, 2015a y 2015b). Por ejemplo, como lo hemos mencionado anteriormente, los géneros de economía (diversos tipos de informes técnicos, artículos de investigación, balances anuales, declaraciones de gastos, etc.) son géneros escritos por expertos y dirigidos a otros expertos o a un público específico. Asimismo, estos géneros se caracterizan por estar constituidos por múltiples modos, como el verbal, el gráfico, el matemático, el del color y el tipográfico, entre otros (Parodi, 2010; Parodi y Julio, 2015). Sumado a las características multimodales que presentan los géneros discursivos, la lectura de ellos demanda, en un primer momento, la búsqueda y selección de varios documentos para que, en un segundo momento, la información contenida en los múltiples textos y sus múltiples modos sea integrada en una representación mental coherente compleja, que potencialmente permita la construcción e integración de un nuevo conocimiento a partir de ellos (Rouet y Britt, 2014).

En este sentido, comprender textos de estos géneros de economía puede ser de alto impacto no solo para los usuarios del ámbito profesional, sino también para estudiantes universitarios, e inclusive para la población general. Algunos estudios recientes han indagado por los hábitos lectores y el modo en que las disciplinas y el grado de experticia inciden en el procesamiento y la comprensión de textos disciplinares en ámbitos académicos y profesionales (Baron, 2015; Kazanci, 2015; Mangen y Van der Weel, 2016; Parodi et al., 2018; Parodi et al., 2019). A la luz de los hallazgos disponibles, se ha registrado que tanto estudiantes como profesionales en diversos ámbitos declaran una preferencia general y obtienen mejores resultados a favor de la lectura en soporte papel por sobre el digital (Clinton, 2019; Delgado et al., 2018; Kurata et al., 2017; Mizrachi et al., 2018).

\section{La comprensión como actividad guiada por propósitos del lector}

Aunque la investigación en comprensión ha siempre reconocido la importancia de los objetivos de lectura, no fue hasta la década de los noventa en que aparecen teórica y sistemáticamente considerados en el artículo seminal de Graesser et al., (1994). En la propuesta de la teoría construccionista, los autores proponen el principio distintivo de la "búsqueda tras el significado" (search-aftermeaning principle), el cual, entre sus supuestos fundamentales, considera el "supuesto de los objetivos del lector":

The reader goal assumption: the reader constructs a meaning representation that addresses the reader's goals. These goals and meaning representations are normally pitched at deep levels of processing (e.g., se- 
mantics and referential situation model) rather than shallow levels (e.g., wording and syntax) (Graesser $e t$ al., 1994, p. 371).

Con posterioridad, los objetivos o propósitos del lector han sido foco de distintas teorías y modelos de comprensión, llegando a considerarla una dimensión fundamental en su conceptualización (v. g., Britt et al., 2018; Graesser, 2007; Graesser et al., 2015; Graesser y Lehman, 2011; Parodi, 2014; Van den Broek et al., 2001). Si bien, como ya decíamos, existe consenso en otorgarles importancia vital, aún no es del todo claro el espectro de alternativas que los enmarcan.

Por un lado, existe tanto una diversidad denominativa como conceptual: "objetivo", "propósito", "meta”, "tarea”, "instrucción”, “perspectiva”, e incluso, "preguntas". Al respecto, Graesser y Lehman (2011) señalan que existen algunos esfuerzos por tratar de crear taxonomías de objetivos de lectura, aunque, en nuestra opinión, este desafío aún requiere mucha atención teórica y empírica. Algunas de estas diferentes denominaciones evidencian grados diversos de complejidad no claramente delimitados de los distintos procesos cognitivos involucrados. Por ejemplo, en algunas actividades de comprensión puede no estar consignado, de manera explícita, un objetivo preciso, pero ello no quiere decir que el lector no asuma, consciente o inconscientemente, un propósito de lectura propio como "leer para comprender".

Por otro lado, se encuentran denominaciones de objetivos como "leer con perspectiva" (Kaakinen et al., 2002; Kaakinen y Hyönä, 2007) y especificaciones muy detalladas a partir de la lectura de uno o más textos. El objetivo de lectura con perspectiva asume que el lector debe adoptar una posición implícita previa respecto a la información del texto y mantenerla durante la lectura (Kaakinen et al., 2002). No obstante, es posible observar que existen diferentes procesos cognitivos relacionados con cada tipo de objetivo, pero no se aprecia en la bibliografía una revisión sistemática de ellos.

La Tabla 1, adaptada de Moreno-de-León (2018), resume las tres primeras aproximaciones teóricas abordadas en este artículo (comprensión de un único texto eminentemente verbal, comprensión de un texto multimodal y comprensión de múltiples textos verbales), prestando especial atención a cómo se atiende a los objetivos de lectura en cada teoría.

Tabla 1 Teorías que abordan los objetivos de lectura

\begin{tabular}{|c|c|c|c|c|c|}
\hline Teoría & Modelo & Enfoque & Autores & Noción de comprensión & Objetivo de lectura \\
\hline \multirow[t]{3}{*}{$\begin{array}{l}\text { Comprensión de } \\
\text { un único texto } \\
\text { constituido } \\
\text { únicamente por el } \\
\text { modo verbal }\end{array}$} & Construccionista & Cognitivo & $\begin{array}{l}\text { Graesser, Singer } \\
\text { y Trabasso } \\
\text { (1994) }\end{array}$ & $\begin{array}{l}\text { La comprensión se construye } \\
\text { a partir del supuesto de los } \\
\text { objetivos del lector, el supuesto } \\
\text { de explicación y el supuesto de } \\
\text { coherencia }\end{array}$ & $\begin{array}{l}\text { Propone que el lector } \\
\text { genera sus propios } \\
\text { objetivos de lectura }\end{array}$ \\
\hline & De paisaje & & $\begin{array}{l}\text { Van den Broek, } \\
\text { Young, Tzeng } \\
\text { y Linderholm } \\
\text { (1999) }\end{array}$ & $\begin{array}{l}\text { La comprensión se construye } \\
\text { a medida que se elabora una } \\
\text { representación estable del texto } \\
\text { en la memoria. El resultado es } \\
\text { un paisaje de activaciones que } \\
\text { cambia } \\
\text { dinámicamente }\end{array}$ & $\begin{array}{l}\text { Las normas de coherencia } \\
\text { de los lectores varían } \\
\text { tanto entre ellos, así } \\
\text { como en cada uno de } \\
\text { ellos (por ej., en función } \\
\text { del objetivo de lectura) }\end{array}$ \\
\hline & $\begin{array}{l}\text { Construcción- } \\
\text { Integración }\end{array}$ & & Kintsch (1998) & $\begin{array}{l}\text { La comprensión se construye } \\
\text { entre el conocimiento previo y } \\
\text { las marcas linguísticas del texto }\end{array}$ & $\begin{array}{l}\text { Explica los procesos de } \\
\text { comprensión cuando se } \\
\text { lee para aprender }\end{array}$ \\
\hline
\end{tabular}


Tabla 1 Teorías que abordan los objetivos de lectura (Cont.)

\begin{tabular}{|c|c|c|c|c|c|}
\hline Teoría & Modelo & Enfoque & Autores & Noción de comprensión & Objetivo de lectura \\
\hline $\begin{array}{l}\text { Comprensión de } \\
\text { un único texto } \\
\text { multimodal } \\
\text { considerando el } \\
\text { modo verbal y otros } \\
\text { modos (imágenes, } \\
\text { íconos, gráficos, } \\
\text { entre otros) }\end{array}$ & $\begin{array}{l}\text { Aprendizaje } \\
\text { multimedia }\end{array}$ & & $\begin{array}{l}\text { Clark y Mayer } \\
(2008) ; \text { Mayer } \\
(2005)\end{array}$ & $\begin{array}{l}\text { La comprensión se construye } \\
\text { entre la interacción de la } \\
\text { memoria de trabajo (los } \\
\text { estímulos visuales recogidos } \\
\text { ocularmente a partir de palabras } \\
\text { e imágenes) y la memoria de } \\
\text { largo plazo (patrones de lectura } \\
\text { y conocimiento previo) }\end{array}$ & \\
\hline & $\begin{array}{l}\text { Comprensión del } \\
\text { texto e imagen }\end{array}$ & & Schnotz (2014) & $\begin{array}{l}\text { La comprensión se construye } \\
\text { entre cuatro modos: el texto } \\
\text { hablado, las imágenes sonoras, } \\
\text { el texto escrito y imágenes } \\
\text { visuales, a través de la memoria } \\
\text { de trabajo y la memoria de } \\
\text { largo plazo }\end{array}$ & \\
\hline & Código dual & & $\begin{array}{l}\text { Sadoski } \\
\text { y Paivio (2004) }\end{array}$ & $\begin{array}{l}\text { La comprensión se construye } \\
\text { a partir de dos códigos, uno } \\
\text { especializado en el modo verbal } \\
\text { y otro para los otros modos }\end{array}$ & \\
\hline & Comunicabilidad & Psicolingüistico & $\begin{array}{l}\text { Parodi } \\
(2011 \\
2014)\end{array}$ & $\begin{array}{l}\text { La comprensión se construye } \\
\text { a partir de la cognición } \\
\text { situada, interactividad y } \\
\text { socioconstructividad }\end{array}$ & $\begin{array}{l}\text { Propone que el lector } \\
\text { genera sus propios } \\
\text { objetivos de lectura, que } \\
\text { se pueden o no alinear } \\
\text { a la demanda de la } \\
\text { tarea y, eventualmente, } \\
\text { cumplir con ella }\end{array}$ \\
\hline \multirow[t]{3}{*}{$\begin{array}{l}\text { Comprensión de } \\
\text { múltiples textos } \\
\text { considerando } \\
\text { dos o más textos } \\
\text { constituidos } \\
\text { únicamente por el } \\
\text { modo verbal }\end{array}$} & Documentos & Cognitivo & $\begin{array}{l}\text { Britt et } \\
\text { al. (1999) }\end{array}$ & $\begin{array}{l}\text { La comprensión se construye } \\
\text { a partir de las situaciones } \\
\text { (modelo de situación), de } \\
\text { relaciones entre documentos } \\
\text { y en el documento (modelo } \\
\text { intertextual) }\end{array}$ & $\begin{array}{l}\text { Explica los procesos de } \\
\text { comprensión cuando } \\
\text { se lee para seleccionar } \\
\text { textos confiables }\end{array}$ \\
\hline & MD-TRACE & Cognitivo & $\begin{array}{l}\text { Britt, Rouet y } \\
\text { Braasch (2013); } \\
\text { Rouet } \\
(2006)\end{array}$ & $\begin{array}{l}\text { La comprensión se construye } \\
\text { entre dos o más fuentes, en } \\
\text { una representación mental } \\
\text { coherente, sin mezclarlas }\end{array}$ & $\begin{array}{l}\text { Explica los procesos de } \\
\text { comprensión cuando se } \\
\text { lee, para evaluar dos o } \\
\text { más textos y usarlos al } \\
\text { responder preguntas, } \\
\text { estudiar para exámenes } \\
\text { o escribir ensayos }\end{array}$ \\
\hline & Two-step & Cognitivo & $\begin{array}{l}\text { Richter }(2011) \text {; } \\
\text { Richter y Maier } \\
(2017)\end{array}$ & $\begin{array}{l}\text { La comprensión se construye } \\
\text { entre (paso l) la validación de } \\
\text { la información de los textos con } \\
\text { el conocimiento previo, para } \\
\text { (paso 2) responder a una tarea } \\
\text { de lectura en donde se negocia } \\
\text { la integración del contenido del } \\
\text { texto con el conocimiento previo }\end{array}$ & $\begin{array}{l}\text { Explica los procesos de } \\
\text { comprensión cuando } \\
\text { se lee para aprender } \\
\text { de dos o más textos } \\
\text { que contradicen el } \\
\text { conocimiento previo del } \\
\text { lector }\end{array}$ \\
\hline
\end{tabular}


Tabla 1 Teorías que abordan los objetivos de lectura (Cont.)

\begin{tabular}{|c|c|c|c|c|c|}
\hline Teoría & Modelo & Enfoque & Autores & Noción de comprensión & Objetivo de lectura \\
\hline & CAEM & Cognitivo & $\begin{array}{l}\text { List y Alexander } \\
(2017,2018)\end{array}$ & $\begin{array}{l}\text { La comprensión se construye } \\
\text { entre los procesos cognitivos } \\
\text { y afectivos (interés del tema y } \\
\text { hábitos de lectura) }\end{array}$ & $\begin{array}{l}\text { Explica los procesos de } \\
\text { comprensión cuando } \\
\text { se lee para evaluar y } \\
\text { validar dos o más textos } \\
\text { que generan conflicto } \\
\text { cognitivo con las } \\
\text { creencias epistémicas } \\
\text { del lector }\end{array}$ \\
\hline & DIS-C & Cognitivo & $\begin{array}{l}\text { Braasch y } \\
\text { Bråten (2017) }\end{array}$ & $\begin{array}{l}\text { La comprensión se construye a } \\
\text { partir del conjunto de procesos } \\
\text { cognitivos que identifican e } \\
\text { integran la representación } \\
\text { mental de las relaciones } \\
\text { concordantes y las discrepantes } \\
\text { del contenido entre varios } \\
\text { textos }\end{array}$ & $\begin{array}{l}\text { Explica los procesos } \\
\text { de comprensión } \\
\text { cuando se lee para } \\
\text { integrar la información } \\
\text { de dos textos que } \\
\text { se contradicen o } \\
\text { complementan entre sí }\end{array}$ \\
\hline & RESOLV & Cognitivo & $\begin{array}{l}\text { Rouet, Britt y } \\
\text { Durik (2017); } \\
\text { Rouet y Britt } \\
\text { (2014) }\end{array}$ & $\begin{array}{l}\text { La comprensión se construye a } \\
\text { partir de las representaciones } \\
\text { del lector (de la tarea, del } \\
\text { contexto, etc.), recursos del } \\
\text { lector (estrategias de regulación, } \\
\text { etc.) y el contexto físico y social } \\
\text { (objetivo de lectura, audiencia, } \\
\text { facilidades, obstáculos, etc.) que } \\
\text { guían un proceso adaptativo de } \\
\text { lectura }\end{array}$ & $\begin{array}{l}\text { Explica los procesos de } \\
\text { comprensión cuando } \\
\text { se lee para resolver un } \\
\text { problema de lectura de } \\
\text { dos o más textos }\end{array}$ \\
\hline
\end{tabular}

\section{La comprensión de textos multimediales en el siglo XXI}

Al considerar cómo los factores contextuales que afectan a la comprensión han evolucionado en el tiempo, tal vez el cambio más profundo sea el producido por el impacto de las nuevas tecnologías. Los sistemas electrónicos de almacenamiento, recuperación y visualización de información, junto con la cada vez más creciente disponibilidad en Internet, impelen otra vez a la redefinición de la concepción de la comprensión. Ello se debe, en parte, a que las tecnologías que posibilitan la lectura han variado, al ser altamente sensibles a los avances científicos y técnicos de cada sociedad.

En la actualidad, los textos digitales, tanto estáticos como dinámicos, en diferentes dispositivos, como computadoras, teléfonos inteligentes y tablets, dominan el mercado, al ser progresivamente más accesibles a una parte de la población. Con la irrupción de estos nuevos dispositivos es necesario preguntarse qué usos se han dado a estas nuevas tecnologías y, principalmente, qué implicancias tienen para la mente, el cerebro y, por supuesto, para la comprensión.

Contrario a lo que se propone con el término “nativos digitales' (Prensky, 2001), esto es, que quienes nacieron en una época determinada de desarrollo digital tienen destrezas y habilidades avanzadas para utilizar estas nuevas tecnologías, los jóvenes estudiantes no tienen necesariamente mejores competencias para utilizar las nuevas tecnologías digitales (Kirschner y De Bruyckere, 2017). Incluso se ha observado que obtienen 
magros logros al leer textos en dispositivos digitales (Singer-Trakhman et al., 2017). Mas bien, el uso adecuado de estas nuevas tecnologías debe ser explícitamente enseñado, promoviendo nuevas destrezas y competencias para la comprensión multimedial (Goldman, 1997; Goldman et al., 2012; Salmerón y Delgado, 2019).

En este contexto, la comprensión exitosa de textos digitales multimediales requiere el desarrollo de nuevas competencias que tradicionalmente no han sido parte de los planes y programas de enseñanza formal. Es más, tradicionalmente, los planes educativos han estado enfocados en la lectura de un único texto en papel, con predominancia verbal. Para Mangen y Van der Weel (2016), la lectura es una práctica que está mediada por los cambios culturales de cada sociedad. Así, los conceptos actuales de alfabetización y comprensión se van adecuando con el tiempo a los contextos tecnológicos y educativos en los que se insertan. Por este motivo, es necesario entender cómo coevolucionan la comprensión y la tecnología, para entender mejor, por ejemplo, la importancia del paso del papel a la pantalla, así como la influencia de Internet en la comprensión.

Para Salmerón et al. (2018), existen tres competencias claves a la hora de hablar de comprensión multimedial: la navegación, la integración y la evaluación. La navegación se relaciona con la capacidad de manejar la gran cantidad de información disponible en Internet, con el objetivo de asegurar la construcción de una representación coherente de la tarea de lectura, evitando distracciones al buscar en la vasta red de información disponible. La integración, por su parte, requiere la construcción de una representación mental coherente de los textos leídos y de su combinación con el conocimiento previo del lector, de tal manera que ambas se asocien en la memoria. Por último, la evaluación de la información es un aspecto clave en la comprensión digital, pues los filtros tradicionales, asociados a editoriales e instituciones de diversa índole que decidían qué textos eran publicados y difundidos, representan solo una sección de los medios disponibles en la internet. En la red, cualquier persona puede publicar información a través de múltiples medios y plataformas: todos son potenciales creadores de significados. Por ello, los lectores deben evaluar continuamente la información, en cuanto a su relevancia y la confiabilidad de los textos que leen en función de las tareas de lectura (Salmerón et al., 2018).

Todo lo anterior abre un importante debate en torno a la enseñanza y la alfabetización para lo que sigue del siglo XXI (Leu et al., 2004; Alexander y The Disciplined Reading and Learning Research Laboratory, 2012). Con la predominancia, por un lado, del uso de Internet para la navegación y búsqueda de información y, por otro, con la masificación de los distintos dispositivos para la visualización y lectura de textos en ambientes educativos, es necesario enfatizar en el desarrollo de competencias específicas para un uso exitoso de estas nuevas tecnologías. Por ejemplo, cada vez más, la comprensión implica la búsqueda, coordinación e integración de múltiples textos multimodales y multimediales (List y Alexander, 2018), ya que diversas investigaciones han reportado la dificultad de los lectores en comprender a partir de múltiples textos multimediales, en ambientes donde la búsqueda exitosa de la información puede ser una tarea altamente compleja (Bråten et al., 2008; Keil y Kominsky, 2013). Junto con ello, las diferentes potencialidades de estas nuevas tecnologías para la creación y la combinación de diversos recursos semióticos, como el verbal, el gráfico, el matemático, entre otros, llevan a desafiar lo que entendemos por "comprensión" y "alfabetización”, ya sea tanto en contextos educativos, académicos y profesionales.

\section{Proyecciones y desafíos actuales y futuros}

El recorrido propuesto en este artículo es, ciertamente, una mirada sesgada del complejo fenómeno de la comprensión de textos escritos. Hemos optado por privilegiar construir y brindar una 
panorámica de la evolución de los estudios científicos que dan cuenta de este macroproceso, en un progresivo proceso de complejización conceptual, atendiendo a los procesos inferenciales como núcleo fundamental, a los objetivos o propósitos de lectura, y a los géneros del discurso académicos y profesionales, así como a la disciplinariedad. Todo ello, como advertimos en la introducción, desde un lector típico ideal, con habilidades estándar y motivado por la lectura.

Nos hemos centrado en dar cuenta del modo en que los ojos de los investigadores han ido sistemática y progresivamente abordando la complejización del fenómeno de la comprensión de textos escritos y, por ende, su reconceptualización. En esta mirada teórica y empírica, hemos conceptualizado el procesamiento de un único texto eminentemente verbal, es decir, compuesto solo por palabras, hasta considerar la lectura de múltiples textos multimodales, en donde, a modo de ejemplo, hemos revisado informes económicos que suelen emplear numerosos gráficos para construir los significados técnicos especializados.

Por cierto, somos conscientes de que no hemos aquí abordado, entre otros, metodologías de investigación a nivel de ciencia básica y aplicada, programas de desarrollo de la competencia lectora en diversas instancias educativas y su apoyo al aprendizaje, técnicas de evaluación de la comprensión tanto para investigación como para propósitos educativos, relación entre comprensión y memoria en general, comprensión y envejecimiento, comprensión y patologías del lenguaje.

No obstante lo anterior, y pese al vasto aporte de robustas teorías, aún los conocimientos disponibles en distintos frentes son escasos o extremadamente preliminares y parciales, todo lo cual impele a avanzar en investigaciones teóricas y empíricas que, por ejemplo, consideren variables como los diferentes formatos $(v \cdot g$., digital, papel) y dispositivos ( $v . g$., tabletas, computadoras). Asimismo, como hemos venido proponiendo a lo largo de este artículo, creemos que se debe también avanzar en construir una teoría más integral e integradora que explique cómo leen las personas ante objetivos de lectura más representativos del mundo real - por ejemplo, leer para integrar múltiples textos multimodales y multimediales-, la cual es una tarea bastante común en los ámbitos personal, académico y profesional en la actualidad.

\section{Referencias}

Alemdag, E., y Cagiltay, K. (2018). A systematic review of eye tracking research on multimedia learning. Computers and Education, 125, 413-428. https://doi. org/10.1016/j.compedu.2018.06.023

Alexander, P., y The Disciplined Reading and Learning Research Laboratory (2012). Reading into the future: Competence for the 21st century. Educational Psychologist, 47(4), 259-280. https://doi.org/10.10 $80 / 00461520.2012 .722511$

Banco Central de Chile. (2018). Informe de politica monetaria diciembre 2018. https:// www.bcentral.cl/ contenido/ - / detalle/ informe-de-politica-monetaria-diciembre-2018-4

Baron, N. (2015). Words onscreen. The fate of reading in a digital world. Oxford University Press.

Baron, N., Calixte, R., y Havewala, M. (2017). The persistence of print among university students: An exploratory study. Telematics and Informatics, 34(5), 590-604. https://doi.org/10.1016/j. tele.2016.11.008

Braasch, J., Bråten, I., y McCrudden, M. (Eds.). (2018). Handbook of multiple source use. Routledge. https:// doi.org/10.4324/9781315627496

Braasch, J., y Bråten, I. (2017). The discrepancy-induced source comprehension (D-ISC) model: Basic assumptions and preliminary evidence. Educational Psychologist, 52(3), 167-181. https://doi.org/10.10 $80 / 00461520.2017 .1323219$

Bråten, I., Strømsø, H., y Samuelstuen, M. (2008). Are sophisticated students always better? The role of topic-specific personal epistemology in the understanding of multiple expository texts. Contemporary Educational Psychology, 33(4), 814-840. https:// doi.org/10.1016/j.cedpsych.2008.02.001

Britt, M., Perfetti, C., Sandak, R., y Rouet, J.-F. (1999). Content integration and source separation in learning from multiple texts. En S. Goldman, A. Graesser y P. van den Broek (Eds.), Narrative comprehension, causality, and coherence. Essays in honor of Tom Trabasso (pp. 209-233). Erlbaum. 
Britt, M., Rouet, J.-F., y Braasch, J. (2013). Documents as entities: Extending the situation model theory of comprehension. En M. A. Britt, M. Goldman y J.-F. Rouet (Eds.), Reading - From words to multiple texts (pp. 160-179). Routledge.

Britt, M., Rouet, J-F., y Durik, A. (2018). Literacy beyond text comprehension. A theory of purposeful reading. Taylor y Francis Group. https:// doi.org/10.4324/9781315682860

Britt, M., y Sommer, J. (2004). Facilitating textual integration with macro-structure focusing tasks. Reading Psychology, 25(4), 313-339. https://doi. org/10.1080/02702710490522658

Britton, B., y Graesser, A. (Eds.). (1996). Models of understanding text. Erlbaum.

Clark, R. C., y Mayer, R. E. (2008). e-Learning and the science of instruction. Pfeiffer.

Clinton, V. (2019). Reading from paper compared to screens: A systematic review and meta-analysis. Journal of Research in Reading, 42(2), 288-325. https:// doi.org/10.1111/1467-9817.12269

Coseriu, E. (1992). Competencia lingüistica. Elementos de la teoria del hablar. Gredos.

DeVega,M.(2005).Lenguaje,corporeidadycerebro:unarevisión crítica. Revista Signos, 38(58), 157-176. https:// doi.org/10.4067/S0718-09342005000200002

De Vega, M., Glenberg, A., y Graesser, A. (Eds.). (2008). Symbols and embodiment. Debates on meaning and cognition. Oxford University Press. https://doi.org/10.1093/acprof:o so/9780199217274.001.0001

Dehaene, S. (2010). Reading in the brain: The new science of how we read. Penguin Books.

Delgado, P., Vargas, C., Ackerman, R., y Salmerón, L. (2018). Don $\rrbracket_{t}$ throw away your printed books: A meta-analysis on the effects of reading media on reading comprehension. Educational Research Review, 25, 23-38. https://doi.org/10.1016/j. edurev.2018.09.003

Fondo Monetario Internacional (FMI) (2017). Informe anual del FMI 2017. Promover el crecimiento inclusivo. https://www.imf.org/external/pubs/ft/ ar/2017/eng/index.htm

Goldman, S. (1997). Learning from text: Reflections on the past and suggestions for the future. Discourse Processes, 23(3), 357-398. https://doi. org/10.1080/01638539709544997
Goldman, S., Braasch, J., Wiley, J., Graesser, A., y Brodowinska, K. (2012). Comprehending and learning from Internet sources: Processing patterns of better and poorer learners. Reading Research Quarterly, 47(4), 356-381. https://doi.org/10.1002/ RRQ.027

Graesser, A. (2007). An introduction to strategic reading comprehension. En D. McNamara (Coord.), Reading comprehension strategies: Theories, interventions, and technologies (pp. 3-26). Erlbaum.

Graesser, A., Li, H., y Feng, S. (2015). Constructing inferences in naturalistic reading contexts. En E. O囚Brien, A. Cook y R. Lorch (Eds.), Inferences during reading (pp. 290-320). Cambridge University Press. https:// doi.org/10.1017/CBO9781107279186.014

Graesser, A., Singer, M., y Trabasso, T. (1994). Constructing inferences during narrative text comprehension. Psychological Review, 101(3), 371-395. https://doi. org/10.1037/0033-295X.101.3.371

Graesser, A., y Bertus, E. (1998). The construction of causal inferences while reading expository texts on science and technology. Scientific Studies on Reading, 2(3), 247-269. https://doi.org/10.1207/ s1532799xssr0203_4

Graesser, A., y Lehman, B. (2011). Questions drive comprehension of text and multimedia. En M. McCrudden, J. Magliano y G. Schraw (Eds.), Text relevance and learning from text (pp. 53-74). Information Age Publishing.

Gutiérrez-Calvo, M. (1999). Inferencias en la comprensión del lenguaje. En M. de Vega y F. Cuetos (Eds.), Psicolingüistica del español (pp. 231-270). Trotta.

Habel, C., y Acartürk, C. (2011). Causal inference in graphtext constellations: Designing verbally annotated graphs. Tsinghua Science and Technology, 16(1), 7-12. https://doi.org/10.1016/S1007-0214(11)70002-5

Halliday, M. (1978). Language as social semiotics. Arnold.

Halliday, M., y Hasan, R. (1985). Language, context and text: Aspects of language in a social-semiotic perspecti$v e$. Deakin University Press.

Kaakinen, J., Hyönä, J., y Keenan, J. (2002). Perspective effects on online text processing. Discourse Processes, 33(2), 159-173. http://dx.doi.org/10.1207/ S15326950DP3302_03

Kaakinen, J., y Hyönä, J. (2007). Perspective effects in repeated reading: An eye movement study. Memory \& Cognition, 35(6), 1323-1336. https://doi. org/10.3758/bf03193604 
Kazanci, Z. (2015). University students' preferences of reading from a printed paper or a digital screen - A longitudinal study. International Journal of Culture and History, 1(1), 50-53. https://doi.org/10.18178/ ijch.2015.1.1.009

Keil, F., y Kominsky, J. (2013). Missing links in middle school: Developing use of disciplinary relatedness in evaluating Internet search results. PloS One, 8(6), e67777. https://doi.org/10.1371/journal. pone. 0067777

Kintsch, W. (1988). The role of knowledge in discourse comprehension. A construction-integration model. Psychological Review, 95(2), 163-182. https://doi. org/10.1037//0033-295X.95.2.163

Kintsch, W. (1998). Comprehension: A paradigm for cognition. Cambridge University Press.

Kintsch, W. (2013). Revisiting the construction-integration model of text comprehension and its implications for instruction. En D. Alvermann, N. Unrau y R. Ruddell (Eds.), Theoretical models and processes of reading (6. ${ }^{a}$ ed., pp. 807-839). International Reading Association.

Kintsch, W., y Van Dijk, T. (1978). Toward a model of text comprehension and production. Psychological Review, 85(5), 363-394. https://doi. org/10.1037/0033-295X.85.5.363

Kirschner, P., y De Bruyckere, P. (2017). The myths of the digital native and the multitasker. Teaching and Teacher Education, 67, 135-142. https://doi. org/10.1016/j.tate.2017.06.001

Kurata, K., Ishita, E., Miyata, Y., y Minami, Y. (2017). Print or digital? Reading behavior and preferences in Japan. Journal of the Association for Information Science and Technology, 68(4), 884-894. https://doi. org/10.1002/asi.23712

León, J., y Pérez, O. (2003). Taxonomías y tipos de inferencias. En J. León (Coord.), Conocimiento y discurso. Claves para inferir y comprender (pp. 4568). Pirámide.

Leu, D., Kinzer, C., Coiro, J., y Cammack, D. (2004). Toward a theory of new literacies emerging from the Internet and other information and communication technologies. En R. Rudell y N. Unrau (Eds.), Theoretical models and processes of reading (pp. 15701613). International Reading Association.

List, A., y Alexander, P. (2017). Analyzing and integrating models of multiple text comprehension. Educational Psychologist, 52(3), 143-147, https://doi.org/10. 1080/00461520.2017.1328309
List, A., y Alexander, P. (2018). Postscript: In pursuit of integration. Learning and Instruction, 57, 82-85. https:// doi.org/10.1016/j.learninstruc.2018.04.002

Magliano, J., Trabasso, T., y Graesser, A. (1999). Strategic processing during comprehension. Journal of Educational Psychology, 91(4), 615-629. https://doi. org/10.1037/0022-0663.91.4.615

Mangen, A., y Van der Weel, A. (2016). The evolution of reading in the age of digitisation: An integrative framework for reading research. Literacy, 50(3), 116-124. https://doi.org/10.1111/lit.12086

Martinec, R., y Salway, A. (2005). A system for imagetext relations in new (and old) media. Visual Communication, 4(3), 337-371. https://doi. org/10.1177/1470357205055928

Mason, L., Pluchino, P., y Tornatora, M. (2013). Effects of picture labeling on science text processing and learning: Evidence from eye movements. Reading Research Quarterly, 48(2), 199-214. https://doi. org/10.1002/rrq.41

Mayer, R. (2005). Cognitive theory of multimedia learning. En R. Mayer (Ed.), The Cambridge handbook of multimedia learning ( $1^{\text {st }}$ ed., pp. 31-48). Cambridge University Press.

Mayer, R. (2009). Multimedia learning. Cambridge University Press. https://doi.org/10.1017/ CBO9780511811678

McKoon, G., y Ratcliff, R. (1992). Inference during reading. Psychological Review, 99(3), 440-466. https://doi. org/10.1037/0033-295X.99.3.440

McNamara, D. (Ed.). (2007). Reading comprehension strategies. Theories, intervensions and technologies. Erlbaum. https://doi.org/10.4324/9780203810033

McNamara, D., y Magliano, J. (2009). Towards a comprehensive model of comprehension. En B. Ross (Ed.), The psychology of learning and motivation (Vol. 51, pp. 297-384). Elsevier. https://doi.org/10.1016/ S0079-7421(09)51009-2

Mizrachi, D., Salaz, A., Kurbanoglu, S., Boustany, J., y ARFIS Research Group. (2018). Academic reading format preferences and behaviors among university students worldwide: A comparative survey analysis. PloS One, 13(5), 1-32. https://doi.org/10.1371/ journal.pone.0197444

Molina, M. (2018). ¿Cómo leen los profesionales de la economía y la filosofia? Comportamiento lector del Tratado de filosofia y del Informe mensual de estadisticas monetarias y financieras (IMEMF), a través de Eye tracking 
[Tesis de maestría]. Pontificia Universidad Católica de Valparaíso.

Moreno-de-León, T. (2018). Elpapel de los objetivos de lectura en la comprensión de múltiples textos multimodales de economia: estudio con técnicas Eye Tracking [Tesis de maestría]. Pontificia Universidad Católica de Valparaíso.

Otero, M., León, J., y Graesser, A. (Eds.). (2002). The psychology of science text comprehension. Erlbaum.

Parodi, G. (2010). Multisemiosis y lingüística de corpus: artefactos (multi)semióticos en los textos de seis disciplinas en el corpus PUCV-2010. Revista de Lingüistica Teórica y Aplicada, 48(2), 33-70. http:// dx.doi.org/10.4067/S0718-48832010000200003

Parodi, G. (2011).La teoría de la comunicabilidad: notas para una concepción integral de la comprensión de textos escritos. Revisa Signos, 44(76), 145-167. http:// dx.doi.org/10.4067/S0718-09342011000200004

Parodi, G. (2014). Comprensión de textos escritos. La teoría de la comunicabilidad. Eudeba.

Parodi, G. (2015a). Variation across university genres in seven disciplines: A corpus-based study on academic written Spanish. International Journal of Corpus Linguistics, 20(4), 469-499. https://doi. org/10.1075/ijcl.20.4.03par

Parodi, G. (Ed.) (2015b). Géneros académicos y géneros profesionales: accesos discursivos para saber y hacer. Ediciones Universitarias de Valparaíso.

Parodi, G., Burdiles, G., Moreno-de-León, T., y Julio, C. (2018). Hábitos lectores y géneros del discurso en filosofía y en economía y negocios: del discurso académico al discurso profesional. Revista de Lingüistica Teórica y Aplicada, 56(2), 117-152. http:// dx.doi.org/10.4067/S0718-48832018000200117

Parodi, G., Moreno-De León, T., Julio, C., y Burdiles, G. (2019). Generación Google o Generación Gutenberg: hábitos y propósitos de lectura en estudiantes universitarios chilenos. Comunicar, 27(58), 85-94. https://doi.org/10.3916/C58-2019-08

Parodi, G., y Julio, C. (2015). Más allá de las palabras: ¿Puede comprenderse el género discursivo informe de politica monetaria desde un único sistema semiótico predominante? ALPHA, (41), 133-158. http:// dx.doi.org/10.4067/S0718-22012015000200011

Parodi, G., y Julio, C. (2016). ¿Dónde se posan los ojos al leer textos multisemióticos disciplinares? Procesamiento de palabras y gráficos en un estudio experimental con eye tracker. Revista Signos,
49(Sup. 1), 149-183. http://dx.doi.org/10.4067/ S0718-09342016000400008

Perfetti, C., Rouet, J-F., y Britt, M. (1999). Towards a theory of documents representation. En H. van Oostendorp y S. Goldman (Eds.), The construction of mental representations during reading (pp. 88-108). Erlbaum.

Pinker, S. (1990). A theory of graph comprehension. En R. Freedle (Ed.), Artificial intelligence and the future of testing (pp. 73-126). Erlbaum.

Prensky, M. (2001). Digital natives, digital immigrants Part 1. On the Horizon, 9(5), 1-6. https://doi. org/10.1108/10748120110424816

Rayner, K., Pollatsek, A., Ashby, J., y Clifton, C. (2012). Psychology of reading. Taylor y Francis. https://doi. org/10.4324/9780203155158

Richter, T. (2011). Cognitive flexibility and epistemic validation in learning from multiple texts. En J. Elen, E. Stahl, R. Bromme y G. Clarebout (Eds.), Links between beliefs and cognitive flexibility (pp. 125-140). Berlin: Springer.

Richter, T., y Maier, J. (2017). Comprehension of multiple documents with conflicting information: A twostep model of validation. Educational Psychologist, 52(3), 148-166. https://doi.org/10.1080/0046152 0.2017 .1322968

Rouet, J. -F. (2006). The skills of document use: From text comprehension to Web-based learning. Psychology Press.

Rouet, J.-F., Britt, M., y Durik, A. (2017). Resolv: Readers' representation of reading contexts and tasks. Educational Psychologist, 52(3), 200-215. https://doi.org/ $10.1080 / 00461520.2017 .1329015$

Rouet, J.-F., y Britt, A. (2014). Multimedia learning from multiple documents. En R. Mayer (Ed.), The Cambridge handbook of multimedia learning (2 ${ }^{\text {nd }}$ ed., pp. 813-841). Cambridge University Press. https:// doi.org/10.1017/CBO9781139547369.039

Royce, T. (1999). Visual-verbal intnersemiotic complementarity in the Economist magazine [Tesis doctoral]. The University of Reading, Centre for Applied Language Studies.

Sadoski, M., y Paivio, A. (2004). A dual coding theoretical model of reading. En R. Ruddell y N. Unrau (Eds.), Theoretical models and processes of reading (4. ${ }^{\mathrm{a}} \mathrm{ed}$., pp. 1329-1362). International Reading Association.

Salmerón, L., Strømsø, H., Kammerer, Y., Stadtler, M., y Van den Broek, P. (2018). Comprehension processes in digital reading. En M. Barzillai, J. Thomson, 
S. Schroeder y P. van den Broek (Eds.), Learning to Read in a Digital World (pp. 91-120). Benjamins. https://doi.org/10.1075/swll.17.04sal

Salmerón, L., y Delgado, P. (2019). Análisis crítico sobre los efectos de las tecnologías digitales en la lectura y el aprendizaje. Cultura y Educación, 31(3), 1-9. https://doi.org/.1037//0033-2909.I26.1.78

Salmerón, L., y Llorens, A. (2019). Instruction of digital reading strategies based on eye-movements modeling examples. Journal of Educational Computing Research, 57(2), 343-359. https://doi. org/10.1177/0735633117751605

Schnotz, W. (2014). Integrated model of text and picture comprehension. En R. Mayer (Ed.), The Cambridge handbook of multimedia learning ( $2^{\text {nd }}$ ed., pp. 72-103). Cambridge University Press. https://doi. org/10.1017/CBO9781139547369.006

Singer-Trakhman, L., Alexander, P., y Berkowitz, L. (2017). Effects of processing time on comprehension and calibration in print and digital mediums. The Journal of Experimental Education, 87(1), 101-115. https:// doi.org/10.1080/00220973.2017.1411877

Strømsø, H. (2017). Multiple models of multiple-text comprehension: A commentary. Educational Psychologist, 52(3), 216-224. https://doi.org/10.10 $80 / 00461520.2017 .1320557$

Strømsø, H., y Bråten, I. (2014). Students' sourcing while reading and writing from multiple web documents. Nordic Journal of Digital Literacy, 9(2), 92-111.

Van den Broek, P., Lorch, R., Linderhol, T., y Gustafson, M. (2001). The effects of readers' goals on inference generation and memory for text. Memory y Cognition, 29(8), 1081-1087. https://doi.org/10.3758/ BF03206376
Van den Broek, P., y Gustafson, M. (1999). Comprehension and memory for texts: Three generations of reading research. En S. Goldman, A. Graesser y P. van den Broek (Eds.), Narrative comprehension, causality, and coherence. Essays in honor of Tom Trabasso (pp. 15-34). Erlbaum.

Van den Broek, P., Young, M., Tzeng, Y., y Linderholm, T. (1999). The landscape model of reading: Inferences and the online construction of a memory representation. En H. van Oostendorp y S. Goldman (Eds.), The construction of mental representations during reading (pp. 71-98). Erlbaum.

Van Dijk, T., y Kintsch, W. (1983). Strategies of discourse comprehension. Academic Press.

Wiley, J., Goldman, S., Graesser, A., Sanchez, C., Ash, I., y Hemmerich, J. (2009). Source evaluation, comprehension, and learning in internet science inquiry tasks. American Educational Research Journal, 46(4), 1060-1106. https://doi. org/10.3102/0002831209333183

Wineburg, S. (1991). Historical problem solving: A study of the cognitive processes used in the evaluation of documentary and pictorial evidence. Journal of Educational Psychology, 83(1), 73-87. https://doi. org/10.1037/0022-0663.83.1.73

Zwaan, R. (2004). The immersed experiencer: Toward an embodied theory of language comprehension. En B. Ross (Ed.), The psychology of learning and motivation (Vol. 44, pp. 35-62). Erlbaum. https://doi. org/10.1016/S0079-7421(03)44002-4

Zwaan, R., y Radvansky, G. (1998). Situation models in language comprehension and memory. Psychological Bulletin, 123(2), 162-185. https://doi. org/10.1037/0033-2909.123.2.162

Cómo citar este artículo: Parodi, G., Moreno-de-León, T., y Julio, C. (2020). Comprensión de textos escritos: reconceptualizaciones en torno a las demandas del siglo xxi. Íkala, Revista de Lenguaje y Cultura, 25(3), 775-795. https:/doi.org/10.17533/udea.ikala.v25n03a10 